\title{
LA FERIA DE ALICANTE (1296-1804)
}

\author{
Enrique CUTILLAS BERNAL
}

Quienes nos enfrentamos al tema de la Feria de Alicante pasamos algunos momentos de asombro al comprobar cómo la concesión de un Privilegio tan importante para cualquier villa o ciudad, fue relegado al olvido, desaprovechándose los grandes beneficios que podían obtener de la feria las gentes de la entonces villa de Alicante.

Resulta difícil comprender que, en tan sólo doscientos años, la Feria de Alicante tuviera que cambiar de fecha cuatro veces, mientras que otras ferias seguían celebrándose en la primera fecha concedida. Y no sólo esto, porque también variaría su emplazamiento y titularidad repetidas veces, hasta el punto de que el historiador llega a dudar si hubo una o tres ferias, si las celebraciones fueron constantes o estuvo desaparecida durante largos períodos.

Hoy nuestra ponencia aporta nueva documentación que permite esclarecer el devenir de la Feria nacida hace ahora setecientos años, la poca inclinación ferial de Alicante y cómo las clases dirigentes de la Ciudad, manipulando la organización en favor de sus intereses personales, consiguieron hacerla fracasar en reiteradas ocasiones, hasta hacerla desaparecer durante largos períodos al provocar la huida de feriantes a otras poblaciones donde no existían presiones fiscales y económicas.

\section{EL NACIMIENTO DE LA FERIA}

Sobre su inicio, la documentación nos demuestra que en 1296

«... el rey don Jaime de Aragón concedía Privilegio perpetuo de Feria para agosto... francos los géneros de todo derecho»'1.

1 A.M.A. Arm. 1, Lib. 50, Fol. 101. 
No debió conseguir el éxito esperado, porque el Consell solicitaba 87 años más tarde que les fuera concedida otra fecha ante la falta de asistencia de feriantes:

«... el señor rey don Pedro de Aragón, dispensó en doze de abril de mil trescientos ochenta y tres, el cambio de fecha, pasando a celebrarse... al mes de diciembre" ${ }^{2}$.

Los feriantes seguían sin acudir a la feria alicantina y 76 años después, nuevamente el Consell solicitaba un nuevo cambio de fecha:

«... el tres de abril de mil quatrocientos cincuenta y nueve... el señor rey don Juan de Aragón (entre otras cosas) confirmó el citado privilegio de Feria... variando el tiempo de la feria del mes de diciembre que entonces se celebraba al de octubre ${ }^{3}$.

Ya convertida Alicante en ciudad, el 2 de enero de 1496, se cumplen ahora cinco siglos, el rey Fernando «confirmó los dos Privilegios antecedentes con franqueza de todos derechos... $\gg^{4}$.

Los primeros años tras la concesión de Jaime II y las cuatro décadas siguientes a la confirmación de Fernando el Católico, debieron ser los dos períodos de mayor rendimiento ferial, pues la Ciudad reconocía años después que la celebración, «tubo su continuado y vio la mencionada feria por toda la serie de las Eras... durante el mes de octubre» ${ }^{5}$.

Esta afirmación nos parece exagerada. Por lo menos deformada, pues no volvemos a tener noticia de la feria (como tal feria de Alicante) hasta el último tercio del siglo XVI\}I.

$Y$ no es que dejara de celebrarse, pero si sufriría transformaciones importantes a partir de 1530, pasando a celebrarse en el Monasterio de la Santa Faz y en los aledaños de San Nicolás, para dar servicio a las gentes de la Ciudad y a los cercanos caseríos de San Juan, Muchamiel y demás partidas de la Huerta. La primitiva feria de Alicante se convirtió en la Feria de la Santa Faz.

\section{LA FERIA EN EL CASERÍO}

Escasa y poco detallada es la documentación que nos aparece sobre la feria del día de la Santa Faz, y las más antiguas citas documentales nos presentan un mercado heterogéneo, con un sólo día de duración. Es algo que encontramos lógico al ser ese, el tiempo que los visitantes permanecian en el caserío.

2 A.M.A. Arm. 1, Lib. 50, Fol. 101.

3 A.M.A. Supra.

4 A.M.A. ibíd.

5 A.M.A. Arm. 1, Lib. 50, Fol.102. 
Pero antes de adentrarnos en el tema, vamos a distinguir tres tipos de feria bajo la advocación de la Santa Faz: la primera, se instalaba en el caserío durante el día de la fiesta; otra que se colocaba primitivamente en las puertas del Ayuntamiento y la Colegial, para aprovechar la afluencia de gentes que acudían para acompañar a la Peregrina; y la tercera, mucho más tardía, que conseguiría la Ciudad en el último tercio del siglo XVIII, también bajo el título de feria de la Santa Faz, pero con ocho días de duración e instalada en Alicante. Su situación fue variable y el éxito efímero.

Por eso debemos tener cuidado para no confundir unas con otras, pues todas ellas nos vienen en los documentos como feria de la Santa Faz.

Pero centrémonos en la más antigua, y que perdura hasta nuestros días: la que se instala en el caserío el día de la romería.

La falta de documentos no nos permite conocer su nacimiento, pero es plausible que naciera sustituyendo a la primitiva feria, al calor de la Peregrina, posiblemente algunos años después de las primeras romerías, cuando la afluencia de devotos permitiera a los feriantes obtener algunas ganancias que compensaran los desplazamientos y los riesgos que estos conllevaban.

Durante el siglo XVI y primer tercio del XVII debieron producirse desplazamientos rápidos e inseguros, instalándose a la salida del sol para marcharse antes de anochecer, pues estaba totalmente prohibido en los momentos de peligro de asaltos, circular de noche por la Huerta. E incluso a mediados del XVI, las mujeres y niños debían abandonar sus casas y sus bienes para refugiarse por las noches en el Monasterio:

«... que de ninguna manera fuera de las torres, Yglesia o Monasterio, quede mujer ni niño a dormir, ni pueda venir ni estar en la dicha guarta asta que esté descubierto y assigurada la dicha guerta... y senyalar personas en la huerta que tengan cargo de visitarla para ver si se retrahen a donde está dicho» ${ }^{6}$.

Con estas condiciones los feriantes no podrían establecerse en los alrededores del Monasterio la noche anterior, ni continuar después de ponerse el sol, el día 17 de marzo. El incumplimiento no sólo conllevaba determinadas sanciones económicas, ya que también estaba prohibido que fueran rescatados en caso de caer en manos de corsarios:

"Que de ninguna manera se pueda rescatar ninguno que se tomare de cualquier condición, que se fuere de las dichas torres, Yglesia o Monasterio, de lo qual se hará provissión y crida, con las penas que pareciere, y modificación de la crida contenida»?.

No se debe olvidar que el peligro berberisco era constante y los desembarcos en

6 A.M.A. Arm. 1, Lib. 9, Fols. 66 y ss.

7 Supra. 
las cercanas playas menudearon hasta casi mediado el siglo XVII. No en vano en mayo de 1638, la abadesa sor Philipa Cisternes, firmaba haber recibido de

«Pedro Borgonión, síndico de dicho Con(ven)to una arrova y media de pólvora, trescientas balas, un roll de cuerdas de arcabús, todo lo qual dise dicho síndico, le ha dado la Ciudad para en caso de necesidad de moros, tenga para poder tirar los escuriles y mosquetes que están en la torre de dicho convento ${ }^{8}$.

El peligro se mantendría al acecho en los años siguientes, pues se ordenaba doblar las guardias y refuerzos ${ }^{9}$.

A partir de mediados el siglo XVII, los peligrosos ataques corsarios fueron espaciándose hasta quedar la situación más tranquila, lo que valdría a los feriantes, el poder acudir en mayor número, configurándose así la feria tal como hoy la conocemos.

Pero así y todo, en estos primeros años el servicio comercial que prestaban los feriantes no pudo ser muy grande. Sin duda se establecieron paradas que procuraban los géneros más necesarios a los visitantes y gentes de la huerta, pero tenemos constancia de que las mismas religiosas obtenían mercancías por otros medios, incluso en los mismos barcos que los transportaban. Al menos esto se deduce de una orden de los jurados, fechada el 23 de noviembre de 1551, por la que obligaban a las monjas a pagar al arrendador de los derechos de la sisa mayor, los derechos correspondientes a las mercancías que habían comprado las religiosas Clarisas del Monasterio de la Santa Faz, mercancías que:

«... fueron desembarcadas y luego se arrepintieron y volvieron a embarcar en el mismo buque... ${ }^{10}$.

También estaria en relación la importancia de la feria con el número de visitantes que ese día se desplazaba al Monasterio, sin duda grande para la población de aquellos años, pero que, según datos de una rogativa que pasaría a la historia como multitudinaria, se habrían reunido 800 personas $^{11}$. Es más, en la tardía fecha de 1763, sólo habitaban en el caserío de Santa Faz 29 vecinos.

Sí tenemos noticias de la feria que se celebraba el día 17 de marzo en los siglos primeros; sólo nos indican su existencia y pocos datos más aportan, comenzando a dar noticias documentadas a principios del siglo XVIII.

En 1701 la ciudad de Murcia había enviado a Alicante un bando que hacía saber la ratificación de Felipe $V$ del antiguo privilegio de feria para aquella ciudad, comunicando a los feriantes alicantinos las fechas en que se efectuaría para su posible asis-

8 A.M.A. Arm. 5, Lib. 16, Fol. 151.

9 Ibíd. Fol. 206.

10 A.M.A. Arm. 5, Lib. 67, Fol. 1.

11 A.M.A. Arm. 5, Caja n 24, s/fol. 
tencia. Ante esta noticia los jurats alicantinos escribían días más tarde a los de Murcia solicitando información de las prerrogativas concedidas por la Corona y si el nuevo monarca les había respetado todos los privilegios o había abolido algunos.

El 15 de marzo de 1702, los regidores de la capital del Segura respondían a las autoridades municipales alicantinas que el monarca se había servido:

«... confirmar y aprovar a esta Ciudad, por Real Despacho de 19 de noviembre del año próximo pasado, todos sus privilegios, gracias, franquezas, livertades y prerrogativas, y entre ellas que se buelba a restablecer y zelebrar en esta Ciudad, una feria que tenía principio desde el día 25 de agosto y los 15 días siguientes, de cada un año, con todas las franquezas y calidades que expresa la zitada real confirmación, y el privilegio original que obtubo esta Ciudad del Señor Rey don Alfonso el décimo, su data a 19 de maio de $1304 \ldots{ }^{12}$.

Nacía así la idea entre los jurats alicantinos de conseguir una feria que debería celebrarse el día de la Santa Faz no sólo como hasta entonces se venía haciendo, con un día de duración, sino alargándola hasta ocho días más.

Para conseguir estos propósitos daban los jurats orden a don José Caballero, su procurador en la Corte, para que intentara conseguir que se celebrara la feria durante ocho días a partir del 17 de marzo, ya que la actual feria de la Santa Faz «por introducción solo tiene uno...» ${ }^{13}$.

Con fecha 17 de abril de 1702, los jurats escribian nuevamente al citado procurador instándole a que la solicitud pareciera pedida por las monjas, para que:

"se comprehenda que las señoras Religiosas, son las que desean tener ocho días de mercado franco de todo género de mercaderías, ropas, ganados y demás cossas comerciables, y que nuestra obligación, solicita por su consuelo. $Y$ assí en todo casso salga la concesión a instancia de la abadesa y monjas, $y$ se pida el informe con el sobreescrito de Mercado franco, porque no comprehendan essos Señores del Consejo, que es esta gracia, de perjuicio a los derechos reales que se cobran en esta Ciudad ' $^{14}$.

Una muestra más de la utilización que para sus intereses hizo la Ciudad de la fundación del Monasterio.

Lo que no esperaban los jurats cuando decidieron solicitar la feria a nombre de las Clarisas, sería que estas elevaran al Consejo de Aragón un memorial, para que no se concediera la ampliación de la feria, en beneficio de la paz y tranquilidad de un lugar de meditación como era el Monasterio.

12 A.M.A. Arm. 11, Lib. 28, Fol. 10.

13 A.M.A. Arm. 11, Lib. 27, Fol. 28.

14 A.M.A. Arm. 11, Lib. 27, Fol. 31 v. 
Ante la petición de las religiosas, el Consejo de Aragón denegaba la solicitud del Ayuntamiento. El 5 de junio del mismo año, don José Caballero, escribía desde Madrid justificando la negativa del Consejo:

"Ante el memorial que se presentó por la abadesa y convento de la Santísima Faz, respecto a la pretensión de feria... hizo bien el escribano de no presentar el suyo, pedido por la Ciudad» ${ }^{15}$.

No se arredraron los jurados alicantinos y pese a serles denegada la ampliación de la feria, fueron permitiendo una mayor libertad de estancia a los feriantes, hasta el punto que en 1718 se instalaban por tres días, con las consiguientes quejas de las religiosas, que escribían este año al Gobernador pidiendo que evitara la ampliación. La respuesta de éste justificaba la decisión de los regidores, porque los feriantes tenían necesidad de terminar de vender sus mercancías.

Además, el control y organización de la feria no debía ser muy estricto. No consta en estos años mención alguna a la organización y adjudicación de puestos, siendo permanentes las quejas del arrendador de la sisa de la puerta de tierra, doliéndose por la falta de observancia de los Capítulos de arrendamiento:

«... como la falta de manifiestos que no le dan los mercaderes de las ropas de seda que introducen por los correos y de las gentes que se introducen para la feria de la Santa Faz»'16.

La pertenencia de los terrenos en los que se situaban las paradas de los feriantes haría surgir problemas jurisdiccionales con la vecina universidad de San Juan; y en los momentos de segregación, se agudizarían las disputas.

En 1766, Pascual Fita denunciaba ante la Ciudad que el día nueve de abril anterior, durante la feria de la Santa Faz, se habían introducido los alcaldes pedáneos, diputados de justicia de San Juan, obligando a algunos feriantes a pagar licencia de venta. Uno de los feriantes al no haber vendido aún, no pudo abonar lo pedido, siendo detenido y amenazado con armas por los pedáneos quienes «le destrozaron el puesto de juguetes» ${ }^{17}$.

El denunciante exponía las quejas que habían presentado los vendedores, quienes pedían justicia a la Ciudad y su intervención para evitar los altercados que estuvieron a punto de producirse ante el amotinamiento de las gentes que rodearon a los de San Juan.

La denuncia sería elevada a la Real Audiencia y ésta por Real Provisión de 30 de julio citaba a los pedáneos de San Juan y a otros testigos:

15 A.M.A. Arm. 11, Lib. 27, Fol. 45.

16 A.M.A. Arm. 9, Lib. 12, Fol. 74.

17 A.M.A. Arm. 1, Lib. 41, Fol. 128. 
«para verificar los excesos de los referidos alcaldes en averse introducido en la Feria de la Santísima Faz, que se celebra en el territorio de esta Ciudad y procedido a exigir algunas cantidades de los feriantes y prender a quien se resistía» ${ }^{18}$.

La causa se fallaba el 15 de diciembre de 1766, condenando a los alcaldes a pagar las costas, ordenándoles que no podían exigir cantidad alguna en la citada feria ${ }^{19}$.

La falta de organización daría lugar a que en la feria apareciera la picaresca. Si en años atrás se quejaba de ciertas anomalías el arrendador de la sisa de puerta de tierra, en 1772, el señor Merchent denunciaba ante el Cabildo «que en la feria de la Santissima Faz que se celebraba en una de las partidas de esta jurisdicción", había observado el pasado año, cómo el arrendador de pesos y medidas suministraba medidas de caña a los feriantes de paño «que se establecen en la parte de levante del barranco", teniendo que obligarle a que las diera de madera con el sello de la Ciu$\operatorname{dad}^{20}$.

Aunque San Juan en aquellos momentos estaba unido a Alicante por acuerdos económicos, la zona donde el arrendador repartía las medidas antirreglamentarias era término del lugar de San Juan y esto provocaría numerosos incidentes como el de 1766.

En la feria de 1772 el alcalde mayor de Alicante encontró ejerciendo jurisdicción en la Santa Faz al segundo diputado de justicia de San Juan, remitiéndole preso a la Ciudad $^{21}$.

Hasta entonces los feriantes se instalaban en las paradas sin otro canon que el costo de los operarios municipales que montaban los puestos y otro tanto que voluntariamente y por tradición entregaban a las religiosas como limosna, quedando en manos de la Ciudad los repesos y faenas propias del fiel ejecutor. Pero en 1771, un feriante iba a dar a los regidores nuevas ideas para conseguir dinero por los terrenos.

En febrero de 1771 José Richart, tratante vecino de esta Ciudad solicitaba:

«... una de esas paradas de listonería de la feria de la Santísima Faz, juridisción de esta Ciudad... que él ha visto en otras poblaciones en que se celebran ferias de porte, que los respectivos Ayuntamientos distribuyen los puestos a los feriantes para formar sus tiendas ${ }^{22}$.

El solicitante pedía se le concediera un puesto para la siguiente feria, estando dispuesto a abonar la cantidad exigida.

La ocasión podía proporcionar fondos a las arcas municipales y estos siempre eran necesarios, pero sobre todo ese año, en que los diputados del Comercio habían con-

18 A.M.A. Arm. 9, Lib. 56, Fol. 161.

19 A.M.A. Arm. 1, Lib. 41, Fol. 257.

20 A.M.A. Arm. 9, Lib. 66, Fol. 193 v.

21 Ibíd. Fol. 211.

22 A.M.A. Arm. 9, Lib. 65, Fol. 32 v. 
seguido una Real Provisión, fechada en Madrid el 11 de abril de 1771 en la que se ordenaba al "Justicia, Ayuntamiento y Junta de Propios de Mar» que a partir de ese año cesase el derecho de la sisa de puerta de tierra, debiendo dejar libre la entrada de todos los géneros ${ }^{23}$.

En la feria del año siguiente los regidores decidieron organizar los puestos y cobrar un canon por la cesión del suelo, con las consiguientes quejas de los feriantes, por las pérdidas que esto les ocasionaba.

El cese del tributo de la puerta de tierra haría renacer entre los regidores la vieja idea de conseguir que la feria de la Santa Faz se alargara hasta ocho días, algo que había fracasado a principio de siglo, por la negativa de las religiosas.

Y no sólo eso, porque el afán de obtener ingresos llevaría a los regidores a ocuparse de otros temas. Por Resolución Capitular de 9 de marzo de 1771, al tener conocimiento de que en San Vicente y Santa Faz, se habían levantado, "casas unidas y en forma de población» y que sus dueños las alquilaban para viviendas o tiendas, sin que abonaran el Equivalente, acordaban enterarse de los alquileres para gravarlos con el citado impuesto ${ }^{24}$.

Las innovaciones realizadas por los regidores en la feria de 1772 cobrando a los feriantes la superficie ocupada mientras que ellos mismos tenían que levantar la parada por su cuenta, incluso proveerse de maderas para ello, daría lugar a una mayor desorganización y quejas a los frailes del Monasterio, quienes expusieron el caso a la abadesa.

Días antes de la feria de 1773, la Comunidad del Monasterio escribía al Gobernador, exponiendo el notable perjuicio que sufrían los feriantes:

«... al acerse por sí las paradas para sus venderías, tanto por los transportes de madera, repartimiento de sitios, y a los que vengan forasteros, encontrarse sin tener donde poder vender. $Y$ teniendo proporción la Comunidad de acer por sus donados, las paradas sin perjuicio del público, ni contra lo dispuesto por la resolución de su Magestad, y si beneficio de los mismos feriantes que enquentran echas las paradas sin más que reconocer el trabajo de nuestros hermanos... se sirva concederles su permiso para que agan acer por su quenta las paradas, dando V프 Exa. su comisión al Padre Procurador de este Monasterio, para que con facultades de $V^{a}$ Exa. reparta los puestos para evitar disputas y etiquetas ${ }^{25}$.

El gobernador las autorizaba, sin perjuicio de los derechos y regalías de la Ciudad y de los feriantes, con tal de que todo se ejecutara «en los sitios, paradas, methodo y modo", que beneficiara a los feriantes, al tiempo que prohibía a las monjas que exi-

23 A.M.A. Arm. 9, Lib. 64, Fol. 258 v.

24 A.M.A. Arm. 9, Lib. 65, Fol. 37.

25 A.M.A. Arm. 1, Lib. 51, Fol. 144. 
gieran «otro premio ni interés, ni aún con precepto de limosna que el del legítimo importe del trabajo y costo de hacerlas ${ }^{26}$.

La concesión de organizar la feria a las religiosas, fue un duro golpe para los regidores. No sólo por las pérdidas económicas que representaba, sino por perder algo que siempre habían considerado de su total dominio, y porque veían decrecer sus prerrogativas como patronos del Monasterio y por tanto el dominio de la Comunidad.

Las diferencias por esta concesión del gobernador duraría largos años. De nada sirvieron las alegaciones de los regidores al gobernador, llegando el litigio a ser presentado en la Corte.

Cinco años más tarde, las religiosas seguían organizando las paradas de los feriantes, pero el caso no estaba cerrado. Ante la denuncia de los regidores al Consejo por la actuación del gobernador y corregidor de la Ciudad, éste presentaba su informe el 28 de julio de 1778 en Madrid. Dos días más tarde el procurador de la Ciudad en la Corte remitía al Ayuntamiento copia del citado informe, demostrando los derechos del corregidor en la feria:

"La feria de la Santa Faz, en todos tiempos ha sido dispuesto y arreglada por el Corregidor de esta Ciudad, sin la menor intervención de los regidores, en quanto al señalamiento de sitios y terreno para las paradas de feriantes, quedando sólo a cargo y cuidado de los regidores y diputados del común, últimamente los repesos y demás pertenecientes al fiel executor de mes. Y si en tiempo de mi antecesor el conde de Baillencour asistían los regidores, fue por comicción, encargo o mandato de dicho Governador... ${ }^{27}$.

Don Jorge Dunant, como corregidor de Alicante, rechazaba las acusaciones del Ayuntamiento y demostraba que la petición de los regidores como organizadores de la feria carecía de fundamento y perjudicaba la celebración de ella al dar motivos de descontento a los feriantes, que terminarían por no acudir a ella. Porque no se les podían cobrar impuestos por los terrenos, ya que:

«los feriantes únicamente contribuyeron por el trabajo de los operarios que se ocuparon en la formación de las paradas y la limosna regular que siempre se ha hecho desde antiguo a las monjas del citado Monasterio" ${ }^{28}$.

La imposibilidad por parte de los regidores de organizar la feria, atribución concedida a las religiosas, endurecería más las relaciones entre la Comunidad y los patronos, lo que sería aprovechado por las autoridades de San Juan, que estaban dispuestas a segregarse de la Ciudad.

26 Supra.

27 A.M.A. Arm. 12, Lib. 34, Fols. 124, 126 y 127.

28 Supra. 
El 8 de abril de 1777 un memorial de Bautista Planelles, arrendador en San Juan del peso y medidas, solicitaba del Ayuntamiento de Alicante que no se le pusiera impedimento a sus funciones en la feria de la Santa Faz.

No se haría esperar la respuesta y se le hacía saber que el derecho de pesos y medidas era de la Ciudad y estaba arrendado, sin que San Juan tuviera nada que ver en ello:

«... que los de cántaro de vino, media arrova de azeite y barchilla, pertenecen por mitad a la Real Hacienda y a esta Ciudad. Que los arrendadores de los referidos derehos se hallan en posesión de percibir todos los que causan derechos, pesos y medidas en todo el recinto de la feria de la Santísima Faz" ${ }^{29}$.

Las cosas se complicarían en junio de 1779 , cuando San Juan conseguía la deseada segregación.

El 13 de marzo de 1780 el síndico procurador general informaba a los regidores que al haber ganado San Juan la segregación de Alicante, existía el posible peligro de que en los próximos días de feria de la Santa Faz, pretendieran ejercer jurisdicción «a la otra parte del convento y en la que se llama del barranquet». Para evitarlo acordaban que todos los géneros que se vendieran, lo hicieran dentro de las calles del caserío ${ }^{30}$.

San Juan se había independizado de Alicante, al convertirse en Universidad en 1590, concediéndoles unos términos propios mediante delimitación realizada en 1593, y quedando dentro de ellos «hasta un cuarto de legua que hay de esta con la dicha Ciudad $\$ 31$.

Cuando en 1614 por intereses económicos la joven universidad volvía a unirse a Alicante, las cosas permanecieron tranquilas, hasta que la última segregación de 1779 les recordó que el Ayuntamiento alicantino tenía apropiado parte de ese cuarto de legua, en el que estaba incluido el Monasterio.

No se conformarían los de San Juan con las decisiones de la Ciudad para instalar los puestos dentro de sus límites, por lo que se quejarían a la Real Audiencia, alegando sus derechos.

El fallo de la Audiencia les sería favorable, al demostrar que en 1593 había quedado dentro del término de San Juan:

«El convento y caserío de la Santa Faz (donde) de inmemorial se celebra una feria» ${ }^{32}$.

29 A.M.A. Arm. 9, Lib. 72, Fol. 132.

30 A.M.A. Arm. 9, Lib. 75, Fol. 86.

31 A.M.A. Arm. 1, Lib. 59, Fol. 91.

32 Ibíd. Fols. 66 y ss. 
También dejaba claro que en la feria, los vendedores no sólo habían ocupado la plaza, «sino también el barranquet, tocando al expresado convento» ${ }^{33}$.

El 28 de marzo, un Real Despacho ordenaba a la Ciudad que no hiciese innovación alguna en la feria que debía celebrarse el día 6 de abril próximo, según pedían los síndicos y procurador de San Juan, debiendo celebrarse como de costumbre, bajo pena de 500 libras $^{34}$.

A los regidores alicantinos no les quedaba otra alternativa que acatar lo ordenado, pero acordando que en atención a que el terreno que hasta entonces venía ocupando la feria era perteneciente a la Ciudad, se comunicara a los de San Juan, que se inhibieran de ejercer jurisdicción para "evitar las consecuencias, si se confunden juridisciones» ${ }^{35}$.

La respuesta de las autoridades de San Juan, no dejaba dudas. Pese a saber que su término llegaba hasta un cuarto de legua dentro del cual quedaba el convento por ese año aceptaban llegar «sólo hasta la pared del convento», sin que ello significara que no reclamaran el cuarto de legua en los años posteriores ${ }^{36}$.

No se conformarían los regidores alicantinos y elevaron nueva instancia a la Real Audiencia, pero el fallo favorecería de nuevo a San Juan, al concederles llegar hasta la pared trasera del Monasterio.

La polémica había terminado con descontento para todos, hasta para las religiosas, pues a partir de ese año ya no tenemos constancia de que siguieran organizando la feria, posiblemente por encontrarse ante dos juridiscciones... En este ambiente seguiría celebrándose la fiesta de la Santa Faz, al menos hasta 1804, último año trabajado. La jurisdicción compartida no parece que suscitara nuevos problemas, bien fuera por común acuerdo o bien porque alguna de las partes hiciera dejación de sus derechos.

En 1793 por Resolución Capitular se suspendía la feria por estar declarada la guerra con Francia ${ }^{37}$, intentando evitar posibles disturbios entre los alicantinos y la población francesa asentada en la Ciudad. La idea era bien acogida por el alcalde ordinario de la universidad de San Juan, quien escribía para informarse:

«Acaba de llegar a mi noticia que $\mathrm{V}^{\mathfrak{a}} \mathrm{S}^{\mathrm{a}}$, ha mandado publicarse un bando en esa Ciudad prohibiendo por este año la feria de la Santa Faz, y como ésta se celebra igualmente en el territorio y juridisción de esta universidad, deseo saber, si la providencia de $V^{\mathfrak{a}} S^{\underline{a}}$, es cierta para hacer yo lo mismo en dicha universidad, pues en las actuales circunstancias, quiero uniformar mis procedimientos con los de $\mathrm{V}^{\mathrm{a}} \mathrm{S}^{\mathrm{a}}$, evitando todo genero de ocasión en que pueda acumularse concurso de gentes ${ }^{38}$.

34 A.M.A. Arm. 9, Lib. 75, Fol. 108 y Arm. 1, Lib. 59, Fol. 62.

35 A.M.A. Arm. 9, Lib. 75, Fol. 108.

36 A.M.A. Arm. 1, Lib. 59, Fol. 91.

37 A.M.A. Arm. 9, Lib. 88, Fol. 42 v.

38 A.M.A. Arm. 12, Lib. 49, Fol. 34. 
La calma parecía reinar entre las autoridades de San Juan y Alicante, pero estos últimos tendrían nuevos sobresaltos al recibir noticia de que en el caserío de la Santa Faz se intentaba nombrar un alguacil sin contar con la Ciudad. Los regidores reconocían que eso no debía llevarse a cabo, porque "supondría un primer paso para la segregación» ${ }^{39}$.

Si hasta ahora hemos expuesto la evolución de lo que consideramos realmente la feria de la Santa Faz hasta finales del siglo XVIII, no podemos dejar de referimos a «otra feria», que con el mismo nombre se celebraba en la plaza del Mar y atrio del Ayuntamiento, cercana a las paradas que se montaban junto a San Nicolás. Esta, como la que se celebraba en el Monasterio, y otra que posteriormente obtendría la Ciudad, recibieron la denominación de ferias de la Santa Faz.

Hablemos de estas dos aunque lo hagamos de forma sucinta ya que, como arriba señalamos, el tener todas el mismo nombre pueden llevar a confusiones.

Al mismo tiempo que se celebraba la feria en el cercano caserío y para aprovechar la afluencia de público a la Colegial y las Casas de la Ciudad cuando iba a salir la Peregrina, se instalaban por la mañana del día 17 de marzo una serie de paradas que aprovisionaban al público de las más heterogéneas mercancías. Se trataría de un pequeño núcleo comercial atraído por los posibles clientes que se disponían para la romería y por tratarse de un día festivo en la Ciudad. Desde un principio parece ser que su duración junto a las puertas de San Nicolás y en los atrios del Ayuntamiento, sólo era de un día. Posteriormente, cuando los regidores ampliaron a tres días la feria del caserío, pese a las quejas de la Comunidad, también fueron concedidos dos días más para estas paradas:

«... hizo saber la costumbre que consecuentemente a la feria de la Santísima Faz, ay y ha havido de aserse en esta Ciudad las paradas de la plaza del Mar y atrio de las Casas Consistoriales, por los dos días sucesivos, y que para el efecto estava dispuesta la madera... ${ }^{40}$.

Este nexo entre las dos ferias en un mismo día y con la misma denominación llevaría a equívocos que hicieron confundir una con otra. Posteriormente se enredaría aún más la diferenciación pues nacería otra feria, que arrancaba también bajo la advocación de la Santa Faz. Veamos cómo nace.

En líneas anteriores pudimos comprobar como en 1771, el tratante José Richart proponía a los regidores el cobro de las paradas a los feriantes.

Ese mismo año la Ciudad se veía privada de otra fuente de ingresos al ser abolida la sisa de la puerta de tierra, quedando los géneros libres de entrada; la presión que venían ejerciendo sobre la feria del caserío las autoridades de San Juan... todo un cúmulo de causas que llevarían a los regidores a reconsiderar la posibilidad de conseguir autorización para la feria que había sido denegada en 1702.

39 A.M.A. Arm. 9, Lib. 93, Fol. 126.

40 A.M.A. Arm. 9, Lib. 90, Fol. 85. 
El 27 de abril de 1771 la Ciudad elevaba memorial al Consejo:

«deseando sus Señorías promover la pública utilidad de esta población y considerando ser conducente a este fin, que la feria de la SSma Faz, se extienda a ocho días más, en esta Ciudad y separadamente se establezca un día de mercado cada semana... $>^{41}$.

Para conseguir este proyecto se comisionaba a los señores Pobil y Caturla, quienes debían instruirse en los privilegios que el Ayuntamiento tenía concedidos para esos fines. Los citados comisionados recomendaban al Cabildo que como primer paso se debía solicitar con justificación al Consejo, señalando que la mejor fecha para la feria «era desde 16 de julio hasta el final de mes y para el día semanal de mercado, el mejor día el lunes»42.

Aunque pueda resultar extraño (ya quedó demostrado anteriormente), Alicante carecía de una tradición ferial continuada, pese a tener concedido este privilegio desde el siglo XIII.

En las justificaciones que enviaron Pobil y Caturla, se demostraba esa antigüedad. El primer privilegio había sido concedido por el rey don Jaime, y como fecha para su celebración se les señalaba el mes de agosto, siendo la concesión a perpetuidad, franca de todos los derechos para los géneros que entrasen a la venta.

No tendría éxito la fecha asignada y tras solicitarlo al rey don Pedro de Aragón quedaría confirmada, trasladando la celebración al mes de diciembre, sin que los feriantes sintieran estímulo para frecuentarla. Nuevamente se pediría al rey don Juan de Aragón el cambio de fecha, y el monarca concedía en 1459, que la feria se pasara al mes de octubre.

El 2 de enero de 1496, Fernando el Católico confirmaba todos los privilegios, con franquezas de todos los derechos anteriores. La feria continuó celebrándose en el mes de octubre con mayor o menor suerte, hasta que otras localidades comenzaron a realizar:

«en igual oportunidad de tiempo las ferias de Concentaina y Onteniente, que por su inmediación a aquella Ciudad, arrastraban el concurso a ellas. Que esta novedad impelía a la citada ciudad de Alicante, diputados y síndico personero del Común a restablecer la feria desde diez y seis de julio hasta último del mismo, por ser ocasión de hallarse vacantes otras de este Reyno y seguirse a los principios de agosto la de Orihuela y subcesibamente la de Murcia y Lorcas ${ }^{43}$.

Por estos motivos el Ayuntamiento de Alicante solicitaba del Consejo que aprobara el traslado de la antigua feria al mes de julio y que se le autorizara a tener un día de

41 A.M.A. Arm. 9, Lib. 64, Fol. 65 v.

42 Ibíd. Fol. 69.

43 A.M.A. Arm. 1, Lib. 50, Fol. 101. 
mercado los lunes de cada semana, al igual que lo tenían otras poblaciones del reino, debiendo gozar de franqueza absoluta a todos los géneros sujetos a contribuciones y derechos municipales.

Antes de decidirse el Consejo a otorgar lo solicitado, mandaría informarse de los beneficios o perjuicios que pudiera ocasionar la concesión de la feria solicitada a otras ferias y mercados cercanos y si la Real Hacienda podía sentirse dañada con la concesión. Ante los informes favorables, por Real Resolución de 17 de septiembre de 1772, se concedía a Alicante los privilegios que anteriormente tenía sobre la feria, otorgándole al mismo tiempo la gracia de un día de mercado el lunes de cada semana y ambos en calidad de francos, pero:

«sin perjuicio del derecho de alcavalas que está impuesto sobre los mismos géneros y cobran los diputados del Comercio de aquella Ciudad, para importe del pago de veinte y un mil pesos del cupo del Equivalente de las mismas alcavalas, que se le reparte anualmente con separación de el de los demás vecinos, y estaban obligados a depositar por tercios en la Thesorería del ejercito de dicho Reino, cuia integridad no puede ofenderse con la esención que pretende la espresada Ciudad» ${ }^{44}$.

Los regidores habían intentado conseguir que los géneros que entrasen en la feria y día de mercado quedaran libres hasta del derecho de alcabalas, que cobraban los diputados del comercio como parte del Equivalente que tenían asignado. No debemos olvidar que estos diputados del comercio habían sido los causantes de que la Ciudad perdiera la fuente de ingresos que tenían en la sisa de la puerta de tierra ${ }^{45}$.

Pero esta misma exención ya la habían intentado al solicitar la feria de 1702, porque ese era el motivo que llevó a los regidores de entonces a pedir la feria a nombre de la Comunidad de religiosas del Monasterio, para que no pensaran:

"essos señores del Consejo que es esta gracia de perjuicio a los derechos Reales que se cobra en esta Ciudad ${ }^{46}$.

El anterior privilegio era confirmado el 2 de diciembre de $1772^{47}$, pasando acto seguido a prepararse la feria de 1773 , sin poder imaginarse que mientras ellos tejían sus proyectos, las monjas del Monasterio iban a conseguir del gobernador-corregidor una autorización para organizar las paradas de la feria del caserío, rompiendo los planes que sobre esa feria tenían los regidores.

La nueva feria comenzaba a funcionar en los últimos días del mes de julio de 1773

44 Ibíd. Fol. 104 v.

45 A.M.A. Arm. 9, Lib. 64, Fol. 258 v.

46 A.M.A. Arm. 11, Lib. 27, Fol. 31.

47 A.M.A. Arm. 5, Caja n 40, s/fol. 
en el mismo lugar en el que se colocaban las paradas en el día de la Peregrina, "en el atrio de las Casas Consistoriales" ${ }^{48}$.

Tampoco esta vez acompañaría el éxito a la feria alicantina, pues muy pronto sufriría continuos cambios en su emplazamiento, pasando del primero, a la plaza de Ramiro, luego a la plaza del Mar, y posteriormente volver a su lugar de origen en los atrios de las Casas Consistoriales.

Similar porvenir aguardaba al día elegido para mercado, pues habiendo comenzado el lunes, muy pronto sería trasladado al martes, por la falta de abastecedores, hasta el punto de que don José Antonio Romero, corregidor de Alicante en 1796 se quejaba "de la suma decadencia a que havía llegado, sin presentarse forastero alguno» ${ }^{49}$.

Puede resultar extraño el continuo fracaso de las ferias en Alicante a lo largo de los siglos, posiblemente ocasionado por la mala organización y por la competencia de otras ferias mas llamativas para los vendedores.

También pudo deberse a causas internas, pues en este último período se detectan serias diferencias entre el gobernador y algunos grupos de regidores.

En 1796 tuvieron lugar fuertes presiones de los regidores para evitar la entrada de ciertos géneros forasteros. Se procuraría fomentar el malestar entre los gremios, para que estos embarazaran la llegada de mercaderías, e incluso el alcalde mayor ordenaba encarcelar a algunos vecinos de las poblaciones cercanas, cuando intentaban llegar con sus mercancías para venderlas en el mercado o durante la feria.

En representación elevada a la Audiencia de Valencia por el corregidor de Alicante en 1796, éste denunciaba como la causa de que ningún forastero acudiera al mercado ciertos abusos cometidos:

«... por instancia del clavario del gremio de sarrieros se embargaron a un vecino de Monforte, ciertos capazos, suponiendo aquél, que su ordenanza gremial, tendría el privativo laboreo de dicha especie de manufacturas y que los maestros del oficio reportarían perjuicio en la introducción de dichos obrajes en el mercado. $Y$ en efecto con acuerdo del alcalde mayor, providencia la detención que ya de antemano había hecho por sí mismo el clavario ${ }^{50}$.

Atropellos de este tipo fueron efectuados por los diferentes gremios, deseosos de conservar sus prerrogativas y apoyados por el alcalde $u$ otros regidores, pese a que alguno alzaba su voz en contra de estas anomalías y solicitaba del corregidor que:

«mándase continuar el mercado público en los días señalados a beneficio del común y con admisión de todo género,no siendo de ilícito comercio manufacturas y frutos,según y con la manera que se practica en los demás

48 A.M.A. Arm. 9, Lib. 93, Fol. 122.

49 A.M.A. Arm. 1, Lib. 73, Fol. 239.

50 A.M.A. Arm. 1, Lib. 73, Fol. 240. 
pueblos del Reyno... y que a fin de que los traginantes y conductores forasteros no fuesen molestados con embargos que los empobrecen y retraen de concurrir ${ }^{51}$.

Las requisas quedaban depositadas en manos del regidor diputado de mes y aunque como en esta ocasión el corregidor, tras consultar con los abogados de Ayuntamiento decretaba la devolución de los géneros a los afectados, sin costa alguna para ellos, la realidad mostraba que las detenciones de los forasteros siguieron presentes, propiciando que cada vez acudieran menos vendedores al mercado y a la feria.

Una prueba más de como los regidores actuaban al margen de la ley en beneficio de sus intereses, nos aparece en un Real Decreto de la Audiencia, en el que se ordenaba al Ayuntamiento que respetaran las normas que disponía la Real Provisión del Consejo de 1772 , referente a la feria y mercado:

«... sin permitir que a pretesto de gavelas, ni pagos de derechos gremiales se coarte la introducción y venta de los géneros de lícito comercio con la franqueza correspondiente, en beneficio del Común de aquel pueblo, en los días de mercado de cada semana»52.

Como era costumbre, cuando en Cabildo de 25 de noviembre de 1796 fue leído el fallo de la Audiencia, se prometió acatamiento a la resolución, pero todo serían vanas promesas.

Los abusos reiteradamente permitidos, la disparidad de criterios y una mala organización, terminarían con la feria de ocho días que se celebraba en la ciudad, bajo la advocación de la Santa Faz primero, con la virgen del Carmen después.

Esperamos que con lo aquí expuesto se hayan disipado las dudas que hasta ahora existían, al creer que hubo una feria de la Santa Faz, que se celebraba en el Caserío y luego, por motivos desconocidos, se había trasladado a la Ciudad. Como queda dicho, la feria del Monasterio se celebró allí desde que la gente empezó a acudir en romeria, salvo en contadas ocasiones en que fue suspendida, o en caso de guerra. En la misma fecha se situaba otra en San Nicolás y Casas de la Ciudad, primero de un día de duración y luego con dos días más. Finalmente tendríamos la tercera feria solicitada también como ampliación de la de Santa Faz, pero ésta sería recuperación de antiguos privilegios que tenía concedidos la Ciudad, y se celebraba en la segunda quincena de julio.

51 Ibíd. Fol. $240 \mathrm{v}$.

52 ibíd. Fol. 243. 